\title{
The effects of social comparison orientation on psychological well-being in social networking sites: Serial mediation of perceived social support and self-esteem
}

\author{
Jin Kyun Lee ${ }^{1}$ \\ Accepted: 9 October 2020 / Published online: 14 October 2020 \\ (C) Springer Science+Business Media, LLC, part of Springer Nature 2020
}

\begin{abstract}
This study investigates the effects of the social comparison orientation in social networking sites on psychological well-being. In particular, it examines the mediation effect of perceived social support and self-esteem in the relationship between social comparison orientation and psychological well-being. Data were collected through an online survey with 236 participants in South Korea. The results showed that social comparison orientation negatively influenced psychological well-being. In the relationship between social comparison orientation and psychological well-being, perceived social support had no mediation effect, self-esteem had a significant negative mediation effect, and perceived social support and self-esteem had a negative serial mediation effect. The social comparison orientation in social networking sites could elicit negative emotions, which decrease perceived social support, self-esteem, and psychological well-being. Theoretical and practical implications as well as suggestions for future studies are discussed in detail.
\end{abstract}

Keywords Social comparison orientation $\cdot$ Psychological well-being $\cdot$ Perceived social support $\cdot$ Self-esteem $\cdot$ Social networking sites $\cdot$ SNSs

Social networking sites (SNSs) have become a major channel of daily communication. In 2020, adult social network users in the United States are expected to spend 82 min per day on SNSs, a significant increase from the average daily duration of 76 min predicted in 2019 (Williamson 2020). Partly due to the coronavirus pandemic, contactless social and economic activities have risen drastically on a global scale. Excessive selfdisclosure in SNSs has become a means of connecting with and supporting each other while practicing social distancing during the pandemic (Gao et al. 2020; Nabity-Grover et al. 2020). Studies have shown that while self-disclosure and active interaction with others might be related to better wellbeing and positive mental states, excessive SNS engagement could be associated with poor well-being, loneliness, anxiety, and depression (Hunt et al. 2018; Liu et al. 2019; Reer et al. 2019; Vahedi and Zannella 2019).

Jin Kyun Lee

feature94@hongik.ac.kr

1 School of Advertising \& Public Relations, Hongik University, B303-1, 2639, Sejong-ro, Jochiwon-eup, Sejong-si 30016, South Korea
Few attempts have been made to identify the underlying mechanisms of how the social comparison orientation in SNSs systematically affects individuals' psychological well-being. Social comparison orientation refers to individual differences in the inclination to compare oneself with others (Gibbons and Buunk 1999). Research has found that SNSs can decrease psychological well-being due to unfavorable social comparison or envy (Krasnova et al. 2013; Verduyn et al. 2015). Specifically, Facebook use predicts upward social comparison, which negatively influences individuals' self-esteem and well-being over time, whereas Instagram use has a direct negative effect on psychological well-being (Schmuck et al. 2019). SNS use is a strong predictor of social comparison, which is positively related to the fear of missing out and depressive symptoms through rumination and negatively related to global self-worth, self-perceived physical appearance, and self-perceived social acceptance (Burnell et al. 2019; Feinstein et al. 2013). Individuals with greater social comparison orientation derived from low self-esteem have worse mental health, as they are more likely to hurt themselves psychologically (Jang et al. 2016).

SNSs can facilitate upward social comparison and negatively influence individuals' perceived social support. People who need support find that advice or assistance from others 
who have experienced similar situations is the most helpful. However, having a social comparison orientation makes it difficult for people to find similar comparison targets because they tend to believe that their friends are different from them (Thoits 1986). Given the nature of SNSs, where upward social comparison is dominant (Vogel et al. 2014), SNS users experience a sense of competition rather than receive informational, instrumental, or emotional support (Cohen and Wills 1985; Thoits 1986). Thus, SNSs can be perceived as a source of stress and could threaten individuals' perception of social support availability (Fiore et al. 1983; Trepte et al. 2015), thereby reducing self-esteem (Haferkamp and Krämer 2011; Smith and Pettigrew 2011).

Although studies have examined these factors individually, research has yet to investigate the parallel and sequential relationships between social comparison orientation, perceived social support, self-esteem, and psychological well-being among SNS users in South Korea. South Korea has the third highest rate of active SNS use in the world (Statista 2020a). Over $82 \%$ of young Korean adults aged $20-29$ years reported having used at least one type of SNS (Kim 2019). Instead of seeking entertainment, convenience, and social interaction, Korean college-aged SNS users utilize SNSs to seek social support from existing social relationships (Kim et al. 2011). Thus, examining South Korean SNS users will enhance the understanding of how social comparison orientation, perceived social support, self-esteem, and psychological wellbeing are interrelated. This study will identify the complex relationships between these factors and provide theoretical and practical implications for future research.

\section{Literature Review}

\section{Independent Variable: Social Comparison Orientation}

Social comparison orientation is defined as "the inclination to compare one's accomplishments, one's situation, and one's experiences with those of others" (Buunk and Gibbons 2006, p. 16). Social comparison is a process through which people evaluate themselves and increase self-understanding by comparing themselves with others (Festinger 1954; Helgeson and Mickelson 1995; Taylor et al. 1990). When individuals do not have objective criteria for self-evaluation, they tend to rely on other people and compare their own ability (e.g., who is better or worse) and opinions (e.g., similarities or differences in beliefs and norms) with those of others (Festinger 1954; Taylor et al. 1990). For example, the number of "likes" is used by Facebook users to compare their own selfies with others' selfies (Rosenthal-von der Pütten et al. 2019).

Studies focusing on the positive effect of social comparison orientation on psychological well-being are rare. Meier and
Schäfer (2018) showed that social comparison orientation on Instagram could produce a beneficial emotional reaction to other users' online self-presentations (e.g., benign envy). They found that benign envy fully mediated the positive relationship between the intensive use of Instagram on the one hand and inspiration and positive affect on the other. Park and Baek (2018) reported that different types of emotions (e.g., worry, sympathy, optimism, and inspiration) evoked by social comparison orientation positively affect psychological wellbeing. In a similar vein, Shi et al. (2019) found that different emotions triggered by comparison could positively affect psychological well-being depending on the type of social comparison orientation.

The majority of past studies reported that social comparison orientation had a negative effect on psychological wellbeing. Social comparison orientation is mostly upward social comparison, which is comparing oneself with people who are more capable than or superior to oneself, giving the individual motivation for self-enhancement (Festinger 1954; Wills 1981; Wood 1989). Upward social comparison is triggered by comparison targets' conspicuous self-presentation in SNSs and easy access to their private information in a relevant comparison domain (Fan et al. 2019; Vogel et al. 2014; Wills 1981; Wood 1989). Research has shown that people tend to present their positive aspects in SNSs because they hope to create favorable impressions on others (Brandenberg et al. 2019; Jang et al. 2016; Park and Baek 2018). Positive online selfpresentation could increase pre- and early adolescents' selfesteem via their perceived online popularity (e.g., receiving "likes"), but in the long term, online popularity is negatively associated with self-esteem due to increased dependence on social approval (Meeus et al. 2019). Excessive selfpresentation in selfies negatively affects other Instagram users' evaluation of selfie takers and may therefore lead to negative outcomes (Hong et al. 2020). For Korean females aged 20-39, narcissistic self-presentation in SNSs is negatively related to subjective well-being due to self-discrepancy (Yu and Kim 2020).

Dutch SNS users receive more social support than nonusers do but have a higher level of stress due to unfavorable social comparison or envy (Utz and Breuer 2017). SNS users with higher stress from a social comparison orientation tend to look for more social support online to relieve stress and compensate for their lack of offline support (Utz and Breuer 2017). Increased social comparison orientation when consuming comparison targets' self-presented information evokes envy and jealousy, increases social tension, and causes individuals to brood about various interpersonal concerns (Wang et al. 2018). SNSs can provide individuals experiencing loneliness and emotional instability with social support but higher stress levels resulting from a social comparison orientation toward other SNS users (Berezan et al. 2020; Lo et al. 2018). Passive SNS usage (e.g., direct or indirect content consumption of 
others' idealized SNS profiles, pictures, and status updates) is closely related to social comparison orientation, which reduces social capital and subjective well-being (Burnell et al. 2019; Lin et al. 2018; Liu et al. 2018). Therefore, the following hypothesis is proposed:

H1: Social comparison orientation will have a direct negative effect on psychological well-being.

\section{Mediator Variables: Perceived Social Support and Self-Esteem}

SNSs allow users to connect with others by overcoming geographical and temporal limitations, thus enabling users to search for various types of social support (Lee and Cho 2019; Mazzoni et al. 2016; Pornsakulvanich 2017; Shi et al. 2019; Stefanone et al. 2012). Perceived social support is an individual's perception regarding the availability of social networks that can offer supportive resources (Zimet et al. 1988). The exchange of informational (e.g., information about the environment), instrumental (e.g., goods or services), or emotional support (e.g., liking, love, and empathy) in a social network can be a form of social support when one faces unavoidable adversity (Cohen and Wills 1985; Liu et al. 2018; Thoits 1986). A major benefit of SNSs is that they provide instant access to a diverse network of weak ties (Ellison et al. 2007), allowing users to receive support in the form of support messages and increasing their life satisfaction. In addition, for close ties, SNSs facilitate offline interaction to provide social support (Liu et al. 2018). People tend to trust support providers who are experiencing similar problems or have similar backgrounds (Thoits 1986; Wright 2000). Users securing social support are likely to exhibit community commitment, show continuous SNS use intention (Lin et al. 2016), experience less depression (Wang et al. 2019), and have increased psychological well-being (Verduyn et al. 2017).

However, the promotion of upward social comparison by SNSs can negatively influence users' perceived social support (Vogel et al. 2014). If individuals perceive most of their friends are different from them, they might believe that few people can offer them support. In the context of the social comparison of ability, one is highly likely to experience a sense of competition (Festinger 1954); thus, friends on SNSs can be seen as a source of stress, which may threaten one's perception of social support availability (Fiore et al. 1983). Furthermore, social comparison processes occurring in SNSs can elicit negative psychological outcomes, such as mental affliction and anxiety (Gibbons 1986; Gibbons and Gerrard 1989). Looking at superior others who are better at their egoinvested domains could generate a sense of relative deprivation-the feeling that one has fewer possessions, achievements, or abilities than others (Smith and Pettigrew
2011). One may also feel pressure to catch up with the superior other to reach a balanced psychological state (Festinger 1954). For example, upward social comparison with attractive body images displayed on SNSs is closely related to body image concerns for women and depressive mood and anxiety about weight (Powell et al. 2018). Burke and Rains (2019) found that weight concern was greater for respondents who compared themselves with attractive body images than for respondents who compared themselves with similar people. People also reported more distress when they were exposed to the Facebook profiles of people with successful careers (Haferkamp and Krämer 2011). Based on these arguments, the following hypothesis is proposed:

H2: Perceived social support will have a negative parallel mediation effect in the relationship between social comparison orientation and psychological well-being.

Social comparison orientation can also have a negative impact on self-esteem (Ho and Ito 2019; Ozimek et al. 2018; Schmuck et al. 2019; Yang and Robinson 2018). Self-esteem refers to the evaluation of oneself (Rosenberg 1965). Receiving positive social support and using SNSs as a platform for self-reflection are positively related to self-esteem, whereas comparing oneself with others results in decreased self-esteem (Krause et al. 2019). Schmuck et al. (2019) reported that SNSs such as Facebook predicted upward social comparison, which negatively influenced individuals' self-esteem and psychological well-being over time. Ho and Ito (2019) also found that young adults who were deeply into consumption-oriented engagement in SNSs experienced low self-esteem, anxiety, and overspending. These relationships were mediated by social comparison orientation, which was, in turn, moderated by individuals' materialistic values (Ho and Ito 2019). Overemphasis on materialistic values can make the social comparison orientation more salient, which negatively affects self-esteem. According to self-regulation theory, people with vulnerable narcissism are likely to have a social comparison orientation when using SNSs to achieve narcissistic goals, such as comparing themselves with superior others, to compensate for their lack of self-esteem offline (Ozimek et al. 2018). Therefore, the following hypothesis is proposed:

H3: Self-esteem will have a negative parallel mediation effect in the relationship between social comparison orientation and psychological well-being.

Research has shown that perceived social support and selfesteem are two important variables in the understanding of psychological well-being. Social support from significant others, such as parents, professors, and peers, is a significant predictor of increased self-esteem, greater happiness (Bum and Jeon 2016), and life satisfaction (Trepte et al. 2015). 
High self-esteem and happiness are associated with lower depression (Brandenberg et al. 2019; Wallace et al. 2018). Niu et al. (2018) found that the effect of Chinese adolescents' social comparison in SNSs (i.e., Qzone) on depression was moderated by self-esteem. In other words, compared with those with low self-esteem, participants with high selfesteem were less likely to be affected by depression.

In their study of 257 adolescents from different high schools in Turkey, Ikiz and Cakar (2010) found a significant positive relationship between perceived social support and self-esteem. Zhao et al. (2013) examined the role of social support and self-esteem in the relationship between shyness and loneliness in a sample of 399 college students in China. They found that social support and self-esteem sequentially mediated the impact of shyness on loneliness. Given that social support and self-esteem are related to life satisfaction, optimism, and greater happiness (Bum and Jeon 2016; Ikiz and Cakar 2010; Kane and Ashbaugh 2017; Lian et al. 2018; Martínez-Martí and Ruch 2017), perceived social support may positively affect self-esteem and psychological well-being. Because social comparison orientation negatively affects perceived social support (Vogel et al. 2014), the effect of social comparison orientation on psychological well-being may be negatively mediated by perceived social support and selfesteem in a sequential manner. Thus, the following hypothesis is proposed:

H4: Perceived social support and self-esteem will have a negative sequential mediation effect in the relationship between social comparison orientation and psychological well-being.

Figure 1 shows the research model of this study.

\section{Method}

Based on the literature, a questionnaire using a 7-point Likert scale ranging from 1 (strongly disagree) to 7 (strong agree) was developed to measure social comparison orientation, perceived social support, self-esteem, and psychological well-being. The online survey was administered to a convenience sample of the general public and university students majoring in advertising and public relations in South Korea who indicated that they had previous experience in using SNSs. In 2018 , the social media user penetration rate in South Korea was highest for people aged 18-24 (82.1\%), followed by those aged 25-34 (80.3\%) and those aged 35-44 (64.5\%; Statista 2020b). South Korea is a collectivistic country; its people tend to rely heavily on their existing contacts for social support and information (Kim et al. 2011; Kitayama et al. 2009). At the same time, South Koreans had the highest scores for independent or autonomous-related self-construal in Asia, surpassing China and Malaysia (Lee et al. 2016). Individuals with high autonomous-related self-construal are likely to express their unique personality traits and pursuit their own goals rather than emphasizing connectedness with other individuals (Markus and Kitayama 1991; Singelis 1994). Thus, the sample population of this study provides unique insights into Korean SNS users in relation to other Asian countries.

\section{Sample}

Of the 236 respondents of the online survey, $56.4 \%$ were male and $43.6 \%$ were female. The mean age was 25.8 years; $78.8 \%$ of the participants were in their $20 \mathrm{~s}, 11.3 \%$ were in their $30 \mathrm{~s}$, and $9.9 \%$ were in their 40 s. Of the participants, $39.1 \%$ joined one to three SNS communities, $20.9 \%$ joined four to six, and the rest joined more than six SNS communities. In terms of education level, $71.6 \%$ of the participants were university students, $21.2 \%$ had a bachelor's degree, and the rest had a postgraduate degree. As an incentive to complete the online survey, extra course credit was given to the student participants and gift cards were given to the other participants. All the participants voluntarily joined this study and provided informed consent before answering the questionnaire.

\section{Measures}

Scales from previous research were used to measure all the constructs in the research model. Before the data collection process, a translation-back translation method from English to Korean was used to make sure that the items were properly translated (Beaton et al. 2002), and pretests for the items were carried out on a small sample (Behr 2017; Brislin 1970). To create a social comparison orientation index, eight items were
Fig. 1 Research model. Notes: $\mathrm{H} 1$ is a direct effect. $\mathrm{H} 2$ and $\mathrm{H} 3$ are parallel multiple mediation effects. H4 is a sequential mediation effect

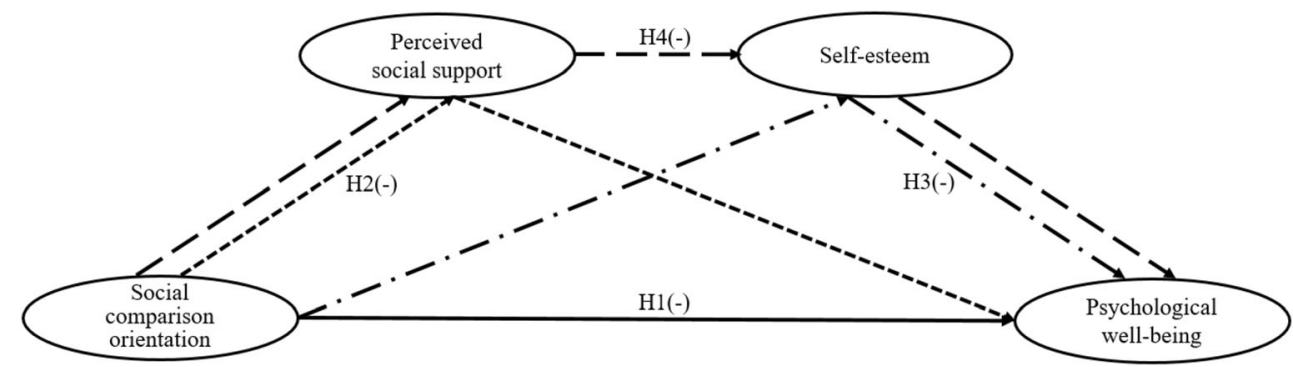


developed in the context of SNSs (Cronbach's alpha $=.94$ ) after slightly modifying the social comparison discrepancy scales (Solberg et al. 2002). Sample items include "In SNSs, I compare myself to others who have a better lifestyle than me," "In SNSs, I compare myself to others who possess more material goods than me," and "In SNSs, I compare myself to others who have accomplished more in life than I have." Table 1 shows the measurement items, means, standard deviations, standardized factor loadings, Cronbach's alpha, construct reliability, and average variance extracted (AVE) for each construct.

Perceived social support was measured based on the Interpersonal Support Evaluation List, which reflects four subdimensions of perceived social support: appraisal support, belonging support, tangible support, and self-esteem support (Cohen et al. 1985). This study focused on the appraisal support dimension, which measures the perceived availability of someone to talk to about one's problems. After running multiple iterations of factor analysis to screen out similar items from the original 10 items concerning the perceived availability of potential appraisal support, four items were adopted (Cronbach's alpha $=.75$ ). Perceived social support items include "I have someone I trust to help solve my problems," "I have no one to share my private worries/fears with," and "I have someone I could turn to for career/job advice."

Six self-esteem items (Cronbach's alpha $=.87$ ) were developed based on the Rosenberg Self-Esteem Scale (Rosenberg 1965). Items include "I feel that I am a person of worth," "I am able to do things as well as most other people," and "I feel I do not have much to be proud of." Finally, 12 items were slightly modified from a study that used 46 items to investigate the construct of psychological well-being among Korean male and female adults (Kim et al. 2001). Psychological wellbeing consists of six subdimensions: self-acceptance, positive relations with others, autonomy, environmental mastery, purpose in life, and personal growth (Ryff 1989). After reviewing the cross-loading values of the factor analysis results and the Cronbach's alpha of the six subdimensions, six pairs of items were carefully selected (Cronbach's alpha $=.85$ ). For example, the autonomy subdimension was measured using two items: "I am able to resist social pressures to think and act in certain ways" and "I am self-determining and independent."

To confirm measurement reliability, convergent, discriminant validity, and confirmatory factor analysis (CFA) were conducted. The CFA showed a reasonable model fit $\left(\chi^{2} / d f=\right.$ $2.11, p<.000$, IFI $=.90, \mathrm{TLI}=.90, \mathrm{CFI}=.90, \mathrm{RMSEA}=.07$ ). Although the $\chi^{2} / d f$ was significant, it is highly sensitive to the sample size. Other fit indices were all within the ranges suggestive of a good fit (Byrne 2013; Salisbury et al. 2002). The standardized factor loadings of each latent construct were greater than .5 with a $t$ value greater than $1.96(p<.001)$, which suggests high convergent validity (Anderson and Gerbing 1988; Hair et al. 1998). The six subdimensions of psychological well-being were retained in the model because the standardized factor loadings of second-order factors were above .6 (Bagozzi and Yi 2012). Although one psychological well-being item (Q2 19) was lower than the standardized factor loading cutoff of .5 , it was maintained because it met alternative cutoff values. Discriminant validity was successfully achieved, as the AVE for the latent construct was greater than the squared intercorrelation of any two variables (Fornell and Larcker 1981). Table 2 shows the AVEs, correlations, and squared correlation coefficients of the constructs.

\section{Results}

SPSS 21.0 and AMOS 21.0 for structural equation modeling (SEM) were used to estimate the parallel and sequential mediation effects of perceived social support and self-esteem. To assess the strength of the linear relationships between constructs, Pearson correlation coefficients were used. Bootstrapping analysis and user-defined estimands were used to identify causal relationships between multiple mediators (Hayes 2017). Bootstrapping is the most appropriate method for measuring indirect effects because it does not make assumptions about the shape of the sampling distribution (Hayes 2017). Successful mediation effects occur when the confidence interval does not include zero (Preacher et al. 2007). Prior to estimating path coefficients with SEM, following the study by Wang et al. (2018), independent sample $t$ tests were conducted to control for gender effects. Wang et al. (2018) found no significant gender differences in social comparison orientation, self-esteem, and subjective well-being, except in passive SNS usage.

In this study, no gender differences were found in social comparison orientation $\left(t(233)=-1.82, p>.05, M_{\text {male }}=3.21\right.$, $\left.S D_{\text {male }}=1.43, M_{\text {female }}=3.56, S D_{\text {female }}=1.43\right)$, perceived social support $\left(t(233)=-.62, p>.05, M_{\text {male }}=5.61, S D_{\text {male }}=\right.$ $\left.1.01, M_{\text {female }}=5.69, S D_{\text {female }}=1.05\right)$, self-esteem $(t(233)=$ $1.90, p>.05, M_{\text {male }}=5.56, S D_{\text {male }}=1.00, M_{\text {female }}=5.30$, $\left.S D_{\text {female }}=1.06\right)$, and psychological well-being $(t(233)=.68$, $p>.05, M_{\text {male }}=4.95, S D_{\text {male }}=.75, M_{\text {female }}=4.88$, $\left.S D_{\text {female }}=.78\right)$. The model fit the data well $\left(\chi^{2} / d f=2.10\right.$, $p<.000, \mathrm{IFI}=.90, \mathrm{TLI}=.90, \mathrm{CFI}=.90, \mathrm{RMSEA}=.06$ ).

Social comparison orientation had a significant direct negative effect on psychological well-being $(\beta=-.16, p<.01$, $S E=.04$ ); thus, Hypothesis 1 was supported. Figure 2 shows the standardized path coefficients of SEM, and Table 3 summarizes the results of hypothesis testing. To test the parallel and sequential mediation effects, this study employed $95 \%$ biased-corrected bootstrapped confidence intervals using 20,000 bootstrapped samples with a maximum likelihood model. Social comparison orientation had no significant parallel mediation effect on psychological well-being through perceived social support $(\beta=-.01, n s, S E=.01,95 \%$ CI 
Table 1 Measurement items overview, reliability and validity measures

\begin{tabular}{|c|c|c|c|c|c|c|c|c|}
\hline Construct & Indicator & Item & Mean & S.D. & $\begin{array}{l}\text { St. factor } \\
\text { loading }\end{array}$ & $\begin{array}{l}\text { Cronbach's } \\
\text { Alpha }\end{array}$ & C.R. & AVE \\
\hline \multirow[t]{8}{*}{$\begin{array}{l}\text { Social comparison } \\
\text { orientation }\end{array}$} & Q7_1 & $\begin{array}{l}\text { In SNSs, I compare myself to others who have a better } \\
\text { lifestyle than me. }\end{array}$ & 3.59 & 1.67 & .83 & \multirow[t]{8}{*}{.94} & \multirow[t]{8}{*}{.94} & \multirow[t]{8}{*}{.64} \\
\hline & Q7_2 & $\begin{array}{l}\text { In SNSs, I compare myself to others who possess more } \\
\text { material goods than me. }\end{array}$ & 3.22 & 1.63 & .81 & & & \\
\hline & Q7_3 & $\begin{array}{l}\text { In SNSs, I compare myself to others who are better looking } \\
\text { than me. }\end{array}$ & 3.54 & 1.79 & .83 & & & \\
\hline & Q7_4 & $\begin{array}{l}\text { In SNSs, I compare myself to others who are living life to the } \\
\text { fullest than I am. }\end{array}$ & 3.84 & 1.76 & .78 & & & \\
\hline & Q7_5 & $\begin{array}{l}\text { In SNSs, I compare myself to others who have accomplished } \\
\text { more in life than I have. }\end{array}$ & 3.81 & 1.83 & .84 & & & \\
\hline & Q7_6 & $\begin{array}{l}\text { In SNSs, I compare myself to others who have wider } \\
\text { relationship with others than me. }\end{array}$ & 3.05 & 1.69 & .74 & & & \\
\hline & Q7_7 & $\begin{array}{l}\text { In SNSs, I compare myself to others who are more popular } \\
\text { than me. }\end{array}$ & 2.82 & 1.58 & .75 & & & \\
\hline & Q7_8 & $\begin{array}{l}\text { In SNSs, I compare myself to others who are happier than } \\
\text { me. }\end{array}$ & 3.05 & 1.73 & .83 & & & \\
\hline \multirow{4}{*}{$\begin{array}{l}\text { Perceived social } \\
\text { support }\end{array}$} & Q3_3 & I have someone I trust to help solve my problems. & 5.80 & 1.20 & .76 & \multirow[t]{4}{*}{.75} & \multirow[t]{4}{*}{.75} & \multirow[t]{4}{*}{.50} \\
\hline & Q3_5* & I have no one to share my private worries/fears with. & 5.81 & 1.25 & .70 & & & \\
\hline & Q3_6* & $\begin{array}{l}\text { If a family crisis arose, I have no one who could give me } \\
\text { good advice. }\end{array}$ & 5.52 & 1.66 & .57 & & & \\
\hline & Q3_7 & I have someone I could turn to for career/job advice. & 5.46 & 1.30 & .65 & & & \\
\hline \multirow[t]{6}{*}{ Self-esteem } & Q1_1 & I feel that I am a person of worth. & 5.95 & 1.18 & .76 & \multirow[t]{6}{*}{.87} & \multirow[t]{6}{*}{.87} & \multirow[t]{6}{*}{.53} \\
\hline & Q1_3* & All in all, I am inclined to think that I am a failure. & 5.51 & 1.38 & .69 & & & \\
\hline & Q1_4 & I am able to do things as well as most other people. & 5.50 & 1.26 & .70 & & & \\
\hline & Q1_5* & I feel I do not have much to be proud of. & 5.11 & 1.52 & .77 & & & \\
\hline & Q1_6 & I take a positive attitude toward myself. & 5.39 & 1.29 & .73 & & & \\
\hline & Q1_7 & On the whole, I am satisfied with myself. & 5.23 & 1.28 & .73 & & & \\
\hline \multirow{12}{*}{$\begin{array}{l}\text { Psychological } \\
\text { well-being }\end{array}$} & Q2_4 & I possess a positive attitude toward the self. & 5.05 & 1.16 & .82 & \multirow[t]{12}{*}{.85} & \multirow[t]{12}{*}{$.89^{* *}$} & \multirow[t]{12}{*}{$.58^{* * *}$} \\
\hline & Q2_10 & I feel positive about past life. & 4.95 & 1.30 & .65 & & & \\
\hline & Q2_6 & $\begin{array}{l}\text { I am capable of strong empathy, affection, and intimacy with } \\
\text { my family and friends. }\end{array}$ & 5.71 & 1.20 & .67 & & & \\
\hline & Q2_19 & I have satisfying and trusting relationships with others. & 5.85 & 1.02 & .49 & & & \\
\hline & Q2_12 & I enjoy setting and achieving my life goals. & 4.40 & 1.54 & .59 & & & \\
\hline & Q2_17 & I have goals in life and a sense of directedness. & 4.98 & 1.44 & .90 & & & \\
\hline & Q2_7 & $\begin{array}{l}\text { I have sense of mastery and competence in managing } \\
\text { everyday affairs. }\end{array}$ & 5.08 & 1.27 & .72 & & & \\
\hline & Q2_14 & I can manage time effectively to finish my job. & 4.46 & 1.27 & .71 & & & \\
\hline & Q2_3 & $\begin{array}{l}\text { I am able to resist social pressures to think and act in certain } \\
\text { ways. }\end{array}$ & 4.73 & 1.29 & .69 & & & \\
\hline & Q2_5 & I am self-determining and independent. & 3.64 & 1.28 & .59 & & & \\
\hline & Q2_15 & I see improvement in myself and behavior over time. & 4.73 & 1.29 & .83 & & & \\
\hline & Q2_18 & I have a feeling of continued development over time. & 5.46 & 1.08 & .57 & & & \\
\hline
\end{tabular}

Notes: * - reversed question, ** - C.R. and AVE of psychological well-being were calculated based on standardized factor loading of each second order factor: self-acceptance (.94), positive relations with others (.62), purpose in life (.73), environmental mastery (.70), autonomy (.65), and personal growth (.88)

$[-.02, .01])$; therefore, Hypothesis 2 was not supported. However, self-esteem exhibited a significant negative parallel mediation effect in the relationship between social comparison orientation and psychological well-being $(\beta=-.20, p<.01$, $S E=.05,95 \%$ CI $[-.30,-.12]$ ), supporting Hypothesis 3 . Finally, the results of bootstrapping analysis revealed that perceived social support and self-esteem had a negative sequential mediation effect in the relationship between social comparison orientation and psychological well-being $(\beta=$ $-.02, p<.05, S E=.01,95 \%$ CI $[-.06,-.01])$. Thus, Hypothesis 4 was supported.

Parallel multiple mediation effects and sequential mediation effects were decomposed into direct effects to gain a better understanding of the complex causal relationships between constructs. The results showed that social comparison orientation had a significant negative effect on perceived 
Table 2 AVE, correlations, and squared correlation coefficients

\begin{tabular}{lllll}
\hline & 1. & 2. & 3. & 4. \\
\hline 1. Social comparison orientation &. $\mathbf{6 4}$ & .04 & .14 & .17 \\
2. Perceived social support & $-.19^{* *}$ &. $\mathbf{5 0}$ & .07 & .08 \\
3. Self-esteem & $-.37^{* *}$ & $.26^{* *}$ &. $\mathbf{5 3}$ & .50 \\
4. Psychological well-being & $-.41^{* *}$ & $.29^{* *}$ & $.71^{* *}$ & $\mathbf{. 5 8}$ \\
\hline
\end{tabular}

Notes: $*-p<.05 . * *-p<.01 . * * * p<.001$. The diagonal elements (bold) represent the AVE values. Upper diagonal represents squared correlations of each construct

social support $(\beta=-.16, p<.05, S E=.05)$ and self-esteem $(\beta=-.35, p<.001, S E=.05)$. Perceived social support had a significant positive effect on self-esteem $(\beta=.25, p<.01$, $S E=.08)$ but no significant effect on psychological wellbeing $(\beta=.02, n s, S E=.06)$. Finally, self-esteem positively affected psychological well-being $(\beta=.84, p<.001$, $S E=.09)$.

\section{Discussion}

This study investigated the effects of social comparison orientation on individuals' psychological well-being in SNSs. It also examined the multiple parallel and sequential mediation effects of perceived social support and self-esteem in the relationship between social comparison orientation and psychological well-being. The results showed that social comparison orientation negatively affected psychological well-being.

Given the tendency toward upward social comparison in SNSs, the study participants were likely to experience negative feelings toward other SNS users who seemed to be doing better than they were. Intensive SNS use could facilitate a social comparison orientation because friends' life stories and events presented on SNSs serve as a cue for social comparison. Researchers have found that social comparison orientation can lead participants to appraise the quality of their current lives (Lee 2014) and is negatively related to users' well-being and self-esteem (Denti et al. 2012; Jang et al. 2016). Social comparison orientation could also cause a discrepancy between the ideal self presented to others and the real self (Gonzales and Hancock 2011; Yu and Kim 2020), thus evoking a sense of depression, deprivation, and distress, as well as aggravating one's mental health (Brandenberg et al. 2019).

Perceived social support did not significantly mediate the relationship between social comparison orientation and psychological well-being. Social comparison orientation had a negative effect on perceived social support, but perceived social support was not significantly related to psychological well-being. The participants of this study might have believed that others who presented only the favorable aspects of their lives were quite different from them. People tend to receive the most support from others who share similar backgrounds, experiences, or situations (Thoits 1986; Vogel et al. 2014). Because of the participants' difficulties in finding similarities with other people, they could have been likely to perceive less social support from their social networks.

According to a dual-path model (Yu and Kim 2020), particularly for Korean women aged 20-40, comparing oneself with others (e.g., others' idealized images) could create a selfdiscrepancy and eventually negatively affect subjective well-being, although it could momentarily increase perceived social support (Vogel and Rose 2016). Self-discrepancy is likely to create negative psychological feelings (Higgins 1987) and emotional vulnerability (Higgins et al. 1986). In addition, because constant seeking for social validation and approval in SNSs is adversely related to self-esteem (Meeus et al. 2019), perceived social support could decrease psychological well-being. Although gender effects were controlled in this study, self-discrepancy might have offset the significant positive relationship between perceived social support and psychological well-being.

This study found that the relationship between social comparison orientation and psychological well-being was negatively mediated by self-esteem. As suggested by Tesser's (1988) theory of self-evaluation maintenance, upward social comparisons in SNSs could elicit negative emotions, which, in turn, lower individuals' self-esteem. Although a few studies have found a positive relationship between the intensity of SNS use and self-esteem (Ellison et al. 2007; Orth et al. 2015; Yu and Kim 2020), other studies have shown that SNS use can result in lower self-esteem because of the negative feedback from upward social comparison (Gilbert et al. 1995; Gonzales and Hancock 2011; Lee 2014). While this study identified a causal link between social comparison orientation and self-esteem, the possibility of a bidirectional causal relationship between lower self-esteem and social comparison orientation should not be ruled out (Lee et al. 2014b). Research has indicated that people with lower self-esteem are more motivated to use SNSs to satisfy their need for social acceptance; they engage more with the Facebook community (Tazghini and Siedlecki 2013), expect more online friends' responses (Lee 2014), and post on SNSs in the hope of receiving more attention and feedback from their networks (Hollenbaugh and Ferris 2014).

Finally, this study found that perceived social support and self-esteem had a significant negative serial mediation effect in the relationship between social comparison orientation and psychological well-being. Research has shown that perceived social support and self-esteem sequentially mediate the relationship between active SNS use and loneliness (Lin et al. 2020). This result is in line with our finding that perceived social support and self-esteem are closely interconnected. In addition to the size and structure of an individual's social network (i.e., the structural aspect of social support, such as 
Table 3 Results of testing proposed hypotheses $(N=235)$

\begin{tabular}{lllllll}
\hline Path & B & SE & C.R. & $\boldsymbol{\beta}$ & Hypothesis & Result \\
\hline Direct effect $(\boldsymbol{a})$ & -.11 & .04 & -2.89 & $-.16^{* * *}$ & $\mathrm{H} 1$ & Accepted \\
$\boldsymbol{b}_{\mathbf{1}}$ & -.10 & .05 & -2.00 & $-.16^{* *}$ & - & - \\
$\boldsymbol{b}_{\mathbf{2}}$ & -.23 & .05 & -4.88 & $-.35^{* * * *}$ & - & - \\
$\boldsymbol{c}_{\mathbf{1}}$ & .25 & .08 & 3.25 & $.25^{* *}$ & - & - \\
$\boldsymbol{c}_{\mathbf{2}}$ & .02 & .06 & .42 & .02 & - & - \\
$\boldsymbol{d}_{\mathbf{1}}$ & .88 & .09 & 9.45 & $.84^{* * * *}$ & - & - \\
Indirect effects & Bootstrapping & BC 95\% CI & & \\
& Estimate & SE & Lower & Upper & & \\
$\boldsymbol{b}_{\mathbf{1}} \boldsymbol{c}_{\mathbf{2}}$ & -.01 & .01 & -.02 & .01 & $\mathrm{H} 2$ & Not accepted \\
$\boldsymbol{b}_{\mathbf{2}} \boldsymbol{d}_{\mathbf{1}}$ & $-.20^{* *}$ & .05 & -.30 & -.12 & $\mathrm{H} 3$ & Accepted \\
$\boldsymbol{b}_{\mathbf{1}} \boldsymbol{c}_{\mathbf{1}} \boldsymbol{d}_{\mathbf{1}}$ & $-.02^{*}$ & .01 & -.06 & -.01 & $\mathrm{H} 4$ & Accepted \\
\hline
\end{tabular}

Model Fit: $\chi^{2} / d f=2.10, p<.000 ; \mathrm{IFI}=.90 ;$ TLI $=.90 ; \mathrm{CFI}=.90 ;$ RMSEA $=.06$

Notes: $*-p<.05 . * *-p<.01 . * * * p<.001 . \mathrm{B}=$ unstandardized path coefficient; $\mathrm{SE}=$ standard error; $\beta=$ standardized path coefficient; $\mathrm{BC}=$ bias corrected; $\mathrm{CI}=$ confidence interval; $\mathrm{a}=$ direct effect of social comparison orientation on psychological well-being; $\mathrm{b}_{1}=$ effect of social comparison orientation on perceived social support; $\mathrm{b}_{2}=$ effect of social comparison orientation on self-esteem; $\mathrm{c}_{1}=$ effect of perceived social support on self-esteem; $c_{2}=$ effect of perceived social support on psychological well-being; $d_{1}=$ effect of self-esteem on psychological well-being

strong vs. weak ties), perceived social support in SNSs could also provide a cost-effective method of building and maintaining relationships. Interacting with friends on SNSs, such as through status updates and by clicking the "like" button, could increase self-esteem support (Meng et al. 2017). Research has shown that individuals with more social support from their networks are more likely to have higher self-esteem, life satisfaction (Kong et al. 2015; Zhao et al. 2013), feeling of social acceptance as well as boosted subjective well-being (Wenninger et al. 2019). However, considering that excessive use of SNSs may trigger social comparison orientation, individuals should use them appropriately to the point where SNSs could help achieve social support, self-esteem, psychological well-being.

\section{Implications}

Excessive SNS use could be detrimental to psychological well-being, as people tend to compare themselves with superior others who are better at their ego-invested domains. The ubiquitousness and accessibility of SNSs allow people to promote artificial and conspicuous self-presentation to fulfill the need for social approval and self-acceptance. When using SNSs to receive social support and recognition, people should protect and maintain their self-esteem. One way to do so is to present themselves authentically, since this relieves depression and increases psychological well-being, life satisfaction, and self-esteem (Grieve and Watkinson 2016; Wang et al. 2019). Authentic self-presentation in SNSs could reduce the self-enhancement motive and social comparison orientation. Authentic self-presentation would be more beneficial to people with lower self-esteem or social skills in offline environments because they are more likely to be addicted to SNSs (Kuss and Griffiths 2011).

Marketers and advertisers should create effective SNS marketing strategies to help individual SNS users experience positive emotions, engage in their lives, develop better relationships with other users, find meaning in life, and gain a sense of achievement (Seligman 2018). For example, marketers could provide people with brand communities where meaningful social values (e.g., commitment to the environment, respect for privacy, and respect for human rights) can be achieved together so that brands can engage with people (Dessart et al. 2015; Lai 2017; Zaglia 2013). Encouraging and cultivating interactions with people, rather than just clicking "like" or "share," would create a favorable environment where people have higher self-esteem and receive social support from other community members. Receiving social support from one's network may lead to positive affective experiences and help individuals achieve authentic happiness through increased self-esteem (Davis 2019; Seligman and Royzman 2003). At the same time, brands would enjoy positive brand reputations and increased brand loyalty and attachment. Finally, policy makers should offer relevant guidelines for the general population on how to use SNSs in productive ways and increase psychological well-being (Verduyn et al. 2017).

This study has several limitations. First, the study did not consider the different characteristics of SNS platforms. For instance, individual responses to SNSs can differ depending on the type of SNS, the content type (textual oriented or visual oriented), and the content orientation (e.g., task, interaction, or self-orientation; Kim et al. 2019; Munar and Jacobsen 2014). Therefore, future research should consider the different types of SNSs in a detailed manner. Second, the psychological well- 


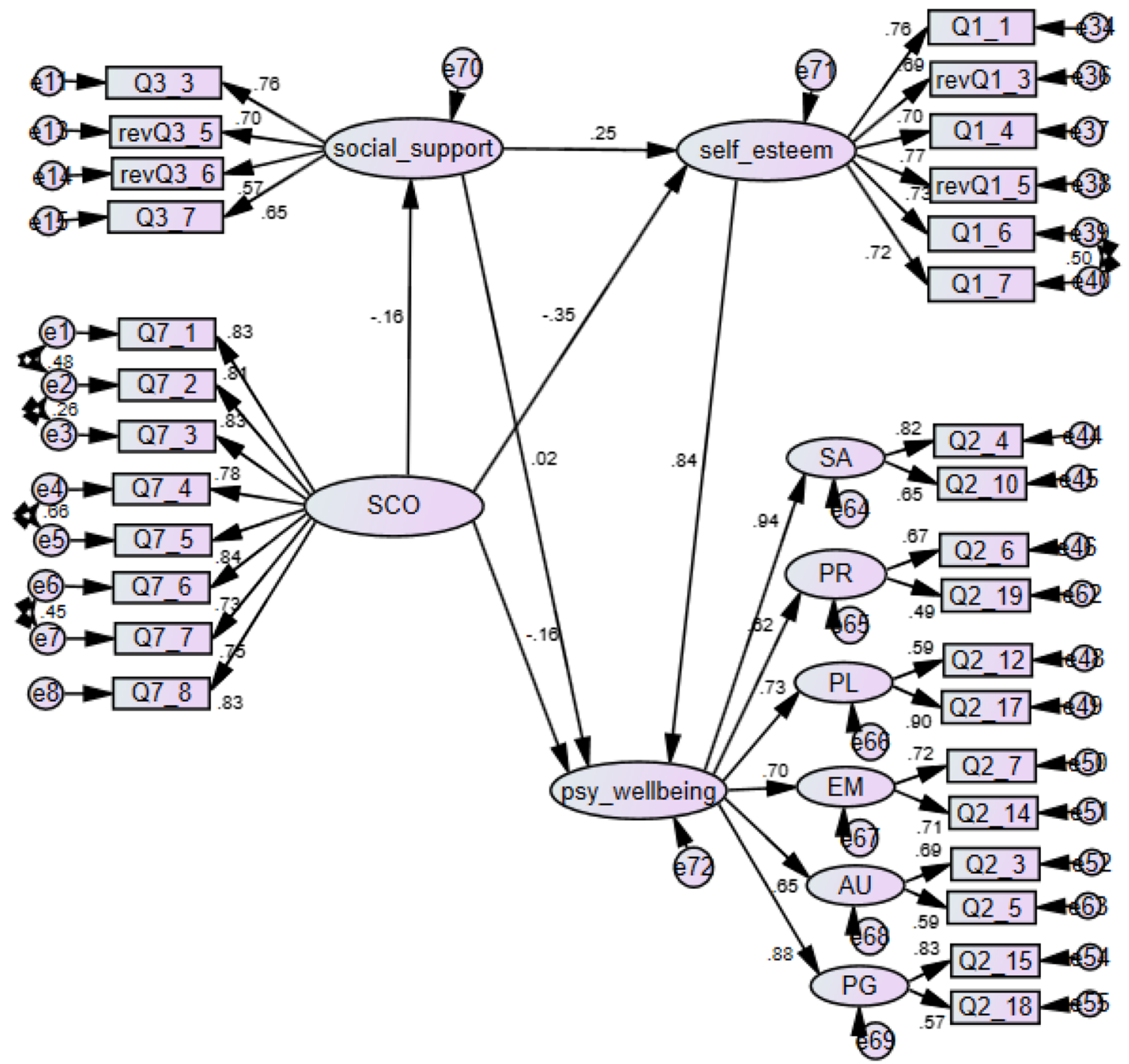

Fig. 2 Standardized path coefficient of structural equation model

being items in the questionnaire were created based on Ryff's (1989) study. Further research should delve into other definitions of psychological well-being and its measurements to capture different subdimensions. Third, individual factors such as personality type (Lee et al. 2014a; Lee et al. 2018), emotional instability, loneliness (Lo 2019; Phu and Gow 2019), and physical disabilities (Lee and Cho 2019) can affect how much social support individuals perceive while interacting with others in similar situations. Thus, future studies are warranted to identify the effects of social comparison orientation together with these individual factors. Finally, social comparison orientation is likely to be affected by cultural gaps (White and Lehman 2005). Generally, Eastern countries are characterized by collectivist values, an interdependent self-concept, and a relationship-oriented culture, whereas Western countries are characterized by individualist values and an independent self-concept (Markus and Kitayama 1991; Singelis 1994). Given the subtle cultural differences even between Eastern countries (Lee et al. 2016), future research should replicate this research model in other Asian countries to compare findings.

Data Availability The datasets generated during and/or analysed during the current study are available from the corresponding author on reasonable request.

\section{Compliance with Ethical Standards}

Conflict of Interest Author Jin Kyun Lee declares that he has no conflict of interest.

Ethical Approval All procedures performed in studies involving human participants were in accordance with the ethical standards of the institutional and/or national research committee and with the 1964 Helsinki declaration and its later amendments or comparable ethical standards.

Informed Consent Informed consent was obtained from all individual participants included in the study. 


\section{References}

Anderson, J. C., \& Gerbing, D. W. (1988). Structural equation modeling in practice: A review and recommended two-step approach. Psychological Bulletin, 103(3), 411-423.

Bagozzi, R. P., \& Yi, Y. (2012). Specification, evaluation, and interpretation of structural equation models. Journal of the Academy of Marketing Science, 40(1), 8-34.

Beaton, D., Bombardier, C., Guillemin, F., \& Ferraz, M. B. (2002). Recommendations for the cross-cultural adaptation of health status measures. New York: American Academy of Orthopaedic Surgeons, $12,1-9$.

Behr, D. (2017). Assessing the use of back translation: The shortcomings of back translation as a quality testing method. International Journal of Social Research Methodology, 20(6), 573-584.

Berezan, O., Krishen, A. S., Agarwal, S., \& Kachroo, P. (2020). Exploring loneliness and social networking: Recipes for hedonic well-being on Facebook. Journal of Business Research, 115, 258265

Brandenberg, G., Ozimek, P., Bierhoff, H. W., \& Janker, C. (2019). The relation between use intensity of private and professional SNS, social comparison, self-esteem, and depressive tendencies in the light of self-regulation. Behaviour \& Information Technology, 38(6), $578-591$.

Brislin, R. W. (1970). Back-translation for cross-cultural research. Journal of Cross-Cultural Psychology, 1(3), 185-216.

Bum, C. H., \& Jeon, I. K. (2016). Structural relationships between students' social support and self-esteem, depression, and happiness. Social Behavior and Personality: An International Journal, 44(11), 1761-1774.

Burke, T. J., \& Rains, S. A. (2019). The paradoxical outcomes of observing others' exercise behavior on social network sites: Friends' exercise posts, exercise attitudes, and weight concern. Health Communication, 34(4), 475-483.

Burnell, K., George, M. J., Vollet, J. W., Ehrenreich, S. E., \& Underwood, M. K. (2019). Passive social networking site use and well-being: The mediating roles of social comparison and the fear of missing out. Cyberpsychology: Journal of Psychosocial Research on Cyberspace, 13(3), article 5. https://doi.org/10.5817/CP2019-35.

Buunk, A. P., \& Gibbons, F. X. (2006). Social comparison orientation: A new perspective on those who do and those who don't compare with others. In S. Guimond (Ed.), Social comparison and social psychology: Understanding cognition, intergroup, relations, and culture (pp. 15-32). Cambridge University Press.

Byrne, B. M. (2013). Structural equation modeling with EQS: Basic concepts, applications, and programming. Routledge.

Cohen, S., \& Wills, T. A. (1985). Stress, social support, and the buffering hypothesis. Psychological Bulletin, 98(2), 310-357.

Cohen, S., Mermelstein, R., Kamarck, T., \& Hoberman, H. M. (1985). Measuring the functional components of social support. In Social support: Theory, research and applications (pp. 73-94). Springer, Dordrecht.

Davis, T. (2019). What is well-being? Definition, types, and well-being skills. Psychology today. Retrieved from: https://www. psychologytoday.com/gb/blog/click-here-happiness/201901/whatis-well-being-definition-types-and-well-being-skills

Denti, L., Barbopoulos, I., Nilsson, I., Holmberg, L., Thulin, M., Wendeblad, M., \& Davidsson, E. (2012). Sweden's largest Facebook study. Gothenburg, Sweden: Gothenburg Research Institute School of Business, Economics and Law, University of Gothenburg.

Dessart, L., Veloutsou, C., \& Morgan-Thomas, A. (2015). Consumer engagement in online brand communities: A social media perspective. Journal of Product \& Brand Management, 24(1), 28-42.
Ellison, N. B., Steinfield, C., \& Lampe, C. (2007). The benefits of Facebook "friends:" social capital and college students' use of online social network sites. Journal of Computer-Mediated Communication, 12(4), 1143-1168.

Fan, X., Deng, N., Dong, X., Lin, Y., \& Wang, J. (2019). Do others' selfpresentation on social media influence individual's subjective wellbeing? A moderated mediation model. Telematics and Informatics, $41,86-102$.

Feinstein, B. A., Hershenberg, R., Bhatia, V., Latack, J. A., Meuwly, N., \& Davila, J. (2013). Negative social comparison on Facebook and depressive symptoms: Rumination as a mechanism. Psychology of Popular Media Culture, 2(3), 161-170.

Festinger, L. (1954). A theory of social comparison processes. Human Relations, 7(2), 117-140.

Fiore, J., Becker, J., \& Coppel, D. B. (1983). Social network interactions: A buffer or a stress. American Journal of Community Psychology, $11(4), 423-439$.

Fornell, C., \& Larcker, D. F. (1981). Structural equation models with unobservable variables and measurement error: Algebra and statistics. Journal of Marketing Research, 18(3), 382-388.

Gao, J., Zheng, P., Jia, Y., Chen, H., Mao, Y., Chen, S., Wang, Y., Fu, H., \& Dai, J. (2020). Mental health problems and social media exposure during COVID-19 outbreak. Plos one, 15(4), e0231924. Retrieved from: https://doi.org/10.1371/journal.pone.0231924.

Gibbons, F. X., \& Buunk, B. P. (1999). Individual differences in social comparison: Development of a scale of social comparison orientation. Journal of Personality and Social Psychology, 76(1), 129-142.

Gibbons, F. X. (1986). Social comparison and depression: Company's effect on misery. Journal of Personality and Social Psychology, $51(1), 140-148$.

Gibbons, F. X., \& Gerrard, M. (1989). Effects of upward and downward social comparison on mood states. Journal of Social and Clinical Psychology, 8(1), 14-31.

Gilbert, D. T., Giesler, R. B., \& Morris, K. A. (1995). When comparisons arise. Journal of Personality and Social Psychology, 69(2), 227236.

Gonzales, A. L., \& Hancock, J. T. (2011). Mirror, mirror on my Facebook wall: Effects of exposure to Facebook on self-esteem. Cyberpsychology, Behavior and Social Networking, 14(1-2), 7983.

Grieve, R., \& Watkinson, J. (2016). The psychological benefits of being authentic on Facebook. Cyberpsychology, Behavior and Social Networking, 19(7), 420-425.

Haferkamp, N., \& Krämer, N. C. (2011). Social comparison 2.0: Examining the effects of online profiles on social-networking sites. Cyberpsychology, Behavior and Social Networking, 14(5), 309314.

Hair, J. F., Black, W. C., Babin, B. J., Anderson, R. E., \& Tatham, R. L. (1998). Multivariate data analysis (Vol. 5, no. 3, pp. 207-219). Upper Saddle River: Prentice hall.

Hayes, A. F. (2017). Introduction to mediation, moderation, and conditional process analysis: A regression-based approach. Guilford publications.

Helgeson, V. S., \& Mickelson, K. D. (1995). Motives for social comparison. Personality and Social Psychology Bulletin, 21(11), 1200 1209.

Higgins, E. T. (1987). Self-discrepancy: A theory relating self and affect. Psychological Review, 94(3), 319-340.

Higgins, E. T., Bond, R. N., Klein, R., \& Strauman, T. (1986). Selfdiscrepancies and emotional vulnerability: How magnitude, accessibility, and type of discrepancy influence affect. Journal of Personality and Social Psychology, 51(1), 5-15.

Ho, H., \& Ito, K. (2019). Consumption-oriented engagement in social network sites: Undesirable influence on personal well-being. European Journal of Marketing, 53(7), 1355-1377. 
Hollenbaugh, E. E., \& Ferris, A. L. (2014). Facebook self-disclosure: Examining the role of traits, social cohesion, and motives. Computers in Human Behavior, 30, 50-58.

Hong, S., Jahng, M. R., Lee, N., \& Wise, K. R. (2020). Do you filter who you are?: Excessive self-presentation, social cues, and user evaluations of Instagram selfies. Computers in Human Behavior, 104, 106159. https://doi.org/10.1016/j.chb.2019.106159.

Hunt, M. G., Marx, R., Lipson, C., \& Young, J. (2018). No more FOMO: Limiting social media decreases loneliness and depression. Journal of Social and Clinical Psychology, 37(10), 751-768.

Ikiz, F. E., \& Cakar, F. S. (2010). Perceived social support and selfesteem in adolescence. Procedia-Social and Behavioral Sciences, $5,2338-2342$.

Jang, K., Park, N., \& Song, H. (2016). Social comparison on Facebook: Its antecedents and psychological outcomes. Computers in Human Behavior, 62, 147-154.

Kane, L., \& Ashbaugh, A. R. (2017). Simple and parallel mediation: A tutorial exploring anxiety sensitivity, sensation seeking, and gender. The Quantitative Methods for Psychology, 13(3), 148-165.

Kim, D. H., Hettche, M., \& Spiller, L. (2019). Incorporating third-party online certifications into a marketing course: The effect of learning style on student responses. Marketing Education Review, 29(3), 193-206.

Kim, M. S., Kim, H. W., \& Cha, K. H. (2001). Analyses on the construct of psychological well-being (PWB) of Korean male and female adults. Korean Journal of Social and Personality Psychology, 15(2), 19-39.

Kim, Y., Sohn, D., \& Choi, S. M. (2011). Cultural difference in motivations for using social network sites: A comparative study of American and Korean college students. Computers in Human Behavior, 27(1), 365-372.

Kim, Y. (2019). KISDI STAT Report, 19-10. Retrieved from: https://stat. kisdi.re.kr/MediaStat/Library/Library_detail1.aspx?MENU_ID= $233 \&$ Division $=1 \&$ seq $=2466$

Kitayama, S., Park, H., Sevincer, A. T., Karasawa, M., \& Uskul, A. K. (2009). A cultural task analysis of implicit independence: Comparing North America, Western Europe, and East Asia. Journal of Personality and Social Psychology, 97(2), 236-255.

Kong, F., Ding, K., \& Zhao, J. (2015). The relationships among gratitude, self-esteem, social support and life satisfaction among undergraduate students. Journal of Happiness Studies, 16(2), 477-489.

Krasnova, H., Wenninger, H., Widjaja, T., \& Buxmann, P. (2013). Envy on Facebook: a hidden threat to users' life satisfaction? Proceedings of the 11th international conference on Wirtschaftsinformatik. Universität Leipzig, Germany. Retrieved from: https://boris.unibe. $\mathrm{ch} / 47080 / 1 /$ WI\%202013\%20Final\%20Submission\%20Krasnova. pdf

Krause, H. V., Baum, K., Baumann, A., \& Krasnova, H. (2019). Unifying the detrimental and beneficial effects of social network site use on self-esteem: A systematic literature review. Media Psychology, 138. Retrieved from: https://www.tandfonline.com/doi/pdf/10.1080/ 15213269.2019.1656646?needAccess $=$ true

Kuss, D. J., \& Griffiths, M. D. (2011). Online social networking and addiction - A review of the psychological literature. International Journal of Environmental Research and Public Health, 8(9), 35283552.

Lai, A. (2017). The value-based consumer. Forbes. Retrieved from: https://www.forbes.com/sites/forrester/2017/03/22/the-valuesbased-consumer/\#6c72895223af

Lee, E., Ahn, J., \& Kim, Y. J. (2014a). Personality traits and selfpresentation at Facebook. Personality and Individual Differences, $69,162-167$

Lee, C., Dickson, D. A., Conley, C. S., \& Holmbeck, G. N. (2014). A closer look at self-esteem, perceived social support, and coping strategy: A prospective study of depressive symptomatology across the transition to college. Journal of Social and Clinical Psychology, $33(6), 560-585$

Lee, H. E., \& Cho, J. (2019). Social media use and well-being in people with physical disabilities: Influence of SNS and online community uses on social support, depression, and psychological disposition. Health Communication, 34(9), 1043-1052.

Lee, J. K., Hansen, S. S., \& Lee, S. Y. (2018). The effect of brand personality self-congruity on brand engagement and purchase intention: The moderating role of self-esteem in Facebook. Current Psychology, 1-13.

Lee, S. L., Kim, J., Golden, K. J., Kim, J. H., \& Park, M. S. A. (2016). A cross-cultural examination of SNS usage intensity and managing interpersonal relationships online: The role of culture and the autonomous-related self-construal. Frontiers in Psychology, 7(376), 1-12. https://doi.org/10.3389/fpsyg. 2016.00376.

Lee, S. Y. (2014). How do people compare themselves with others on social network sites?: The case of Facebook. Computers in Human Behavior, 32, 253-260.

Lian, S. L., Sun, X. J., Yang, X. J., \& Zhou, Z. K. (2018). The effect of adolescents' active social networking site use on life satisfaction: The sequential mediating roles of positive feedback and relational certainty. Current Psychology, 1-9. Retrieved from: https://doi.org/ 10.1007/s12144-018-9882-y.

Lin, S., Liu, D., Liu, W., Hui, Q., Cortina, K. S., \& You, X. (2018). Mediating effects of self-concept clarity on the relationship between passive social network sites use and subjective well-being. Current Psychology, 1-8.

Lin, S., Liu, D., Niu, G., \& Longobardi, C. (2020). Active social network sites use and loneliness: The mediating role of social support and self-esteem. Current Psychology, 1-8.

Lin, X., Zhang, D., \& Li, Y. (2016). Delineating the dimensions of social support on social networking sites and their effects: A comparative model. Computers in Human Behavior, 58, 421-430.

Liu, D., Baumeister, R. F., Yang, C. C., \& Hu, B. (2019). Digital communication media use and psychological well-being: A meta-analysis. Journal of Computer-Mediated Communication, 24(5), 259273.

Liu, D., Wright, K. B., \& Hu, B. (2018). A meta-analysis of social network site use and social support. Computers \& Education, 127, 201-213.

Lo, J. (2019). Exploring the buffer effect of receiving social support on lonely and emotionally unstable social networking users. Computers in Human Behavior, 90, 103-116.

Lo, J., Guo, C., \& Bradley, B. (2018). The buffer effect of receiving social support on SNS exhaustion and SNS satisfaction: An exploratory study of the lonely and emotionally unstable. Proceedings of the 51 st Hawaii international conference on system sciences, 2098-2109. Retrieved from: https://aisel.aisnet.org/hicss-51/dsm/ dsm and communities/6/

Markus, H. R., \& Kitayama, S. (1991). Culture and the self: Implications for cognition, emotion, and motivation. Psychological Review, 98(2), 224-253.

Martínez-Martí, M. L., \& Ruch, W. (2017). Character strengths predict resilience over and above positive affect, self-efficacy, optimism, social support, self-esteem, and life satisfaction. The Journal of Positive Psychology, 12(2), 110-119.

Mazzoni, E., Baiocco, L., Cannata, D., \& Dimas, I. (2016). Is internet the cherry on top or a crutch? Offline social support as moderator of the outcomes of online social support on problematic internet use. Computers in Human Behavior, 56, 369-374.

Meier, A., \& Schäfer, S. (2018). The positive side of social comparison on social network sites: How envy can drive inspiration on Instagram. Cyberpsychology, Behavior and Social Networking, 21(7), 411-417. 
Meeus, A., Beullens, K., \& Eggermont, S. (2019). Like me (please?): Connecting online self-presentation to pre- and early adolescents' self-esteem. New Media \& Society, 21(11-12), 2386-2403.

Meng, J., Martinez, L., Holmstrom, A., Chung, M., \& Cox, J. (2017). Research on social networking sites and social support from 2004 to 2015: A narrative review and directions for future research. Cyberpsychology, Behavior and Social Networking, 20(1), 44-51.

Munar, A. M., \& Jacobsen, J. K. S. (2014). Motivations for sharing tourism experiences through social media. Tourism Management, $43,46-54$.

Nabity-Grover, T., Cheung, C. M., \& Thatcher, J. B. (2020). Inside out and outside in: How the COVID-19 pandemic affects self-disclosure on social media. International Journal of Information Management, 102188. Retrieved from: https://doi.org/10.1016/j.ijinfomgt.2020. 102188

Niu, G. F., Luo, Y. J., Sun, X. J., Zhou, Z. K., Yu, F., Yang, S. L., \& Zhao, L. (2018). Qzone use and depression among Chinese adolescents: A moderated mediation model. Journal of Affective Disorders, 231, 58-62.

Orth, U., Maes, J., \& Schmitt, M. (2015). Self-esteem development across the life span: A longitudinal study with a large sample from Germany. Developmental Psychology, 51(2), 248-259.

Ozimek, P., Bierhoff, H. W., \& Hanke, S. (2018). Do vulnerable narcissists profit more from Facebook use than grandiose narcissists? An examination of narcissistic Facebook use in the light of selfregulation and social comparison theory. Personality and Individual Differences, 124, 168-177.

Park, S. Y., \& Baek, Y. M. (2018). Two faces of social comparison on Facebook: The interplay between social comparison orientation, emotions, and psychological well-being. Computers in Human Behavior, 79, 83-93.

Phu, B., \& Gow, A. J. (2019). Facebook use and its association with subjective happiness and loneliness. Computers in Human Behavior, 92, 151-159.

Pornsakulvanich, V. (2017). Personality, attitudes, social influences, and social networking site usage predicting online social support. Computers in Human Behavior, 76, 255-262.

Powell, E., Wang-Hall, J., Bannister, J. A., Colera, E., \& Lopez, F. G. (2018). Attachment security and social comparisons as predictors of Pinterest users' body image concerns. Computers in Human Behavior, 83, 221-229.

Preacher, K. J., Rucker, D. D., \& Hayes, A. F. (2007). Addressing moderated mediation hypotheses: Theory, methods, and prescriptions. Multivariate Behavioral Research, 42(1), 185-227.

Reer, F., Tang, W. Y., \& Quandt, T. (2019). Psychosocial well-being and social media engagement: The mediating roles of social comparison orientation and fear of missing out. New Media \& Society, 21(7), $1486-1505$

Rosenberg, M. (1965). Society and the adolescent self-image. Princeton: Princeton University Press.

Rosenthal-von der Pütten, A. M., Hastall, M. R., Köcher, S., Meske, C., Heinrich, T., Labrenz, F., \& Ocklenburg, S. (2019). "Likes" as social rewards: Their role in online social comparison and decisions to like other People's selfies. Computers in Human Behavior, 92, 76 86.

Ryff, C. D. (1989). Happiness is everything, or is it? Explorations on the meaning of psychological well-being. Journal of Personality and Social Psychology, 57(6), 1069-1081.

Salisbury, W. D., Chin, W. W., Gopal, A., \& Newsted, P. R. (2002). Better theory through measurement -developing a scale to capture consensus on appropriation. Information Systems Research, 13(1), 91-103.

Schmuck, D., Karsay, K., Matthes, J., \& Stevic, A. (2019). "Looking up and feeling down". The influence of mobile social networking site use on upward social comparison, self-esteem, and well-being of adult smartphone users. Telematics and Informatics, 42, 101240. Retrieved from: https://doi.org/10.1016/j.tele.2019.101240.

Seligman, M. (2018). PERMA and the building blocks of well-being. The Journal of Positive Psychology, 13(4), 333-335.

Seligman, M. E., \& Royzman, E. (2003). Happiness: The three traditional theories. Authentic Happiness Newsletter, (July). Retrieved from: http://pq.2004.tripod.com/happiness_three_traditional theories.pdf

Shi, Y., Luo, Y. L., Liu, Y., \& Yang, Z. (2019). Affective experience on social networking sites predicts psychological well-being off-line. Psychological Reports, 122(5), 1666-1677.

Singelis, T. M. (1994). The measurement of independent and interdependent self-construals. Personality and Social Psychology Bulletin, 20(5), 580-591.

Smith, H. J., \& Pettigrew, T. F. (2011). Relative deprivation theory. The Encyclopedia of Peace Psychology, 67-89. Retrieved form: https:// doi.org/10.1002/9780470672532.wbepp238.

Solberg, E. C., Diener, E., Wirtz, D., Lucas, R. E., \& Oishi, S. (2002). Wanting, having, and satisfaction: Examining the role of desire discrepancies in satisfaction with income. Journal of Personality and Social Psychology, 83(3), 725-734.

Statista (2020a). Active social network penetration in selected countries as of January 2020. Retrieved from: https://www.statista.com/ statistics/282846/regular-social-networking-usage-penetrationworldwide-by-country/

Statista (2020b). Social media user penetration rate in South Korea in 2018 , by age group. Retrieved from: https:/www.statista.com/ statistics/763718/south-korea-social-media-penetration-by-agegroup/

Stefanone, M. A., Kwon, K. H., \& Lackaff, D. (2012). Exploring the relationship between perceptions of social capital and enacted support online. Journal of Computer-Mediated Communication, 17(4), 451-466.

Taylor, S. E., Buunk, B. P., \& Aspinwall, L. G. (1990). Social comparison, stress, and coping. Personality and Social Psychology Bulletin, 16(1), 74-89.

Tazghini, S., \& Siedlecki, K. L. (2013). A mixed method approach to examining Facebook use and its relationship to self-esteem. Computers in Human Behavior, 29(3), 827-832.

Tesser, A. (1988). Toward a self-evaluation maintenance model of social behavior. Advances in Experimental Social Psychology, 21, 181227.

Thoits, P. A. (1986). Social support as coping assistance. Journal of Consulting and Clinical Psychology, 54(4), 416-423. https://doi. org/10.1037/0022-006X.54.4.416.

Trepte, S., Dienlin, T., \& Reinecke, L. (2015). Influence of social support received in online and offline contexts on satisfaction with social support and satisfaction with life: A longitudinal study. Media Psychology, 18(1), 74-105.

Utz, S., \& Breuer, J. (2017). The relationship between use of social network sites, online social support, and well-being. Journal of Media Psychology., 29(3), 115-125.

Vahedi, Z., \& Zannella, L. (2019). The association between self-reported depressive symptoms and the use of social networking sites (SNS): A meta-analysis. Current Psychology, 1-16.

Verduyn, P., Lee, D. S., Park, J., Shablack, H., Orvell, A., Bayer, J., Ybarra, O., Jonides, J., \& Kross, E. (2015). Passive Facebook usage undermines affective well-being: Experimental and longitudinal evidence. Journal of Experimental Psychology, 144(2), 480-488.

Verduyn, P., Ybarra, O., Résibois, M., Jonides, J., \& Kross, E. (2017). Do social network sites enhance or undermine subjective well-being? A critical review. Social Issues and Policy Review, 11(1), 274-302.

Vogel, E. A., \& Rose, J. P. (2016). Self-reflection and interpersonal connection: Making the most of self-presentation on social media. Translational Issues in Psychological Science, 2(3), 294-302.

Vogel, E. A., Rose, J. P., Roberts, L. R., \& Eckles, K. (2014). Social comparison, social media, and self-esteem. Psychology of Popular 
Media Culture, 3(4), 206-222. Retrieved from: https://oi.org/10. 1037/ppm0000047.

Wallace, L., Warkentin, M., \& Benbasat, I. (2018). How do you handle it? Developing a theory of Facebook affordances and envy. In 51st Hawaii International Conference on System Sciences, Hawaii. Retrieved from http://hdl.handle.net/10125/50544.

Wang, J. L., Gaskin, J., Rost, D. H., \& Gentile, D. A. (2018). The reciprocal relationship between passive social networking site (SNS) usage and users' subjective well-being. Social Science Computer Review, 36(5), 511-522.

Wang, P., Wang, X., Zhao, M., Wu, Y., Wang, Y., \& Lei, L. (2019). Can social networking sites alleviate depression? The relation between authentic online self-presentation and adolescent depression: A mediation model of perceived social support and rumination. Current Psychology, 38(6), 1512-1521.

Wenninger, H., Krasnova, H., \& Buxmann, P. (2019). Understanding the role of social networking sites in the subjective well-being of users: A diary study. European Journal of Information Systems, 28(2), 126-148.

White, K., \& Lehman, D. R. (2005). Culture and social comparison seeking: The role of self-motives. Personality and Social Psychology Bulletin, 31(2), 232-242.

Williamson, D. A. (2020). US social media usage: How the coronavirus is changing consumer behavior. eMarketer. Retrieved from: https:// www.emarketer.com/content/us-social-media-usage

Wills, T. A. (1981). Downward comparison principles in social psychology. Psychological Bulletin, 90(2), 245-271. Retrieved from: https:// doi.org/10.1037/0033-2909.90.2.245.
Wood, J. (1989). Theory and research concerning social comparisons of personal attributes. Psychological Bulletin, 106(2), 231-248. Retrieved from: https://doi.org/10.1037/0033-2909.106.2.231.

Wright, K. (2000). Perceptions of on-line support providers: An examination of perceived homophily, source credibility, communication and social support within on-line support groups. Communication Quarterly, 48(1), 44-59.

Yang, C. C., \& Robinson, A. (2018). Not necessarily detrimental: Two social comparison orientations and their associations with social media use and college social adjustment. Computers in Human Behavior, 84, 49-57.

Yu, E., \& Kim, H. C. (2020). Is she really happy? A dual-path model of narcissistic self-presentation outcomes for female facebook users. Computers in Human Behavior, 106328. https://doi.org/10.1016/j. chb. 2020.106328

Zaglia, M. E. (2013). Brand communities embedded in social networks. Journal of Business Research, 66(2), 216-223.

Zhao, J., Kong, F., \& Wang, Y. (2013). The role of social support and self-esteem in the relationship between shyness and loneliness. Personality and Individual Differences, 54(5), 577-581.

Zimet, G. D., Dahlem, N. W., Zimet, S. G., \& Farley, G. K. (1988). The multidimensional scale of perceived social support. Journal of Personality Assessment, 52(1), 30-41.

Publisher's Note Springer Nature remains neutral with regard to jurisdictional claims in published maps and institutional affiliations. 